\title{
Renewable energy source integration into power networks, research trends and policy implications: A bibliometric and research actors survey analysis
}

\author{
放 \\ Emmanuel HACHE ${ }^{a, d, e}$ * \\ Angélique PALLE $^{b, c}$
}

September 10, 2018

\begin{abstract}
This article studies the integration of variable renewable energy sources (RES) into power networks. The main goal is to confront the contents and trends of scientific literature with the eyes and projects of researchers on future topics and issues to be solved, especially in terms of the modeling of electrical systems. The analysis relies on a bibliometric study of the Scopus database on the topic and on an online survey sent to the corresponding authors of the identified papers. The paper analyzes the dynamics of publication, clusters of collaboration, and main topics studied. It then identifies potential research leads, among which unresolved challenges regarding technical aspects, markets and financing issues, and social aspects. The disparity of models and results is still a necessary evil as research is not mature enough to integrate in one model all the very complex parameters of VRE integration into power systems. There is a lack of recurrence, though, such as the impact of emergent technologies or the development of substitute low carbon-emitting technology (other than solar and wind), need to be addressed. The paper also advocates the need for a systemic vision, for both research and policymakers that goes beyond the sole power system.
\end{abstract}

Keywords: Variable renewable energy, bibliometric analysis, scenario, survey, power network, policy JEL Classification: Q42, Q48, Q55

\footnotetext{
is This study received the financial support of the French Alliance for the Coordination of Energy Research (www.allianceenergie.fr) and the authors are very grateful to Marie Françoise Chabrelie and Cécile Dumas for their support. We are also grateful to François Kalaydjian, Philippe Ménanteau and Jérôme Sabathier for insightful comments and suggestions. Of course, any remaining errors are ours. The views expressed herein are strictly those of the authors and are not to be construed as representing those of IFP Énergies Nouvelles.
} 
The authors would like to thank all the researchers, public and private decision-makers working on issues related to the electricity sector in France and abroad for their availability and the quality of their answers during the online survey and during the interviews we conducted between March and September 2017.

a IFP Énergies Nouvelles, 1-4 av. de Bois Préau, F-92852 Rueil-Malmaison, France.

b IRSEM, Ecole Militaire, 1 place Joffre, 75700 Paris SP 07

c Université Paris 1 Panthéon-Sorbonne, UMR Prodig.

d. The French Institute for International and Strategic Affairs, (IRIS), France.

e. EconomiX-CNRS, University of Paris Nanterre, France.

* Corresponding author. Tel.: +331 475268 26; fax: +331 47527066 .

E-mail address: emmanuel.hache@ifpen.fr 


\section{Introduction}

The United Nations Environment Programme's (UNEP) latest report on Global Trend in Renewable Energy Investment in collaboration with Bloomberg New Energy finance (BNEF) recorded an increase in renewable energy (RE) investment of 2\% between 2016 and 2017 to about $\$ 280$ billion, or cumulative amounts since 2010 of about $\$ 2.2$ trillion. Nearly $157 \mathrm{GW}$ of new renewable electricity generation capacity was added, representing nearly $70 \%$ of new electricity generation capacity. The solar sector (38\% of new electricity production capacity) and China (45\% of investments in renewable energy) are at the forefront of the changes observed in the global electricity mix. In 2017, solar, wind, geothermal, biomass, waste, marine energy, and small hydro technologies accounted for $12.1 \%$ of global electricity generation, compared with $11 \%$ in 2016.

Figure 1: Global New Investment in Renewable Energy* (Billion \$US)

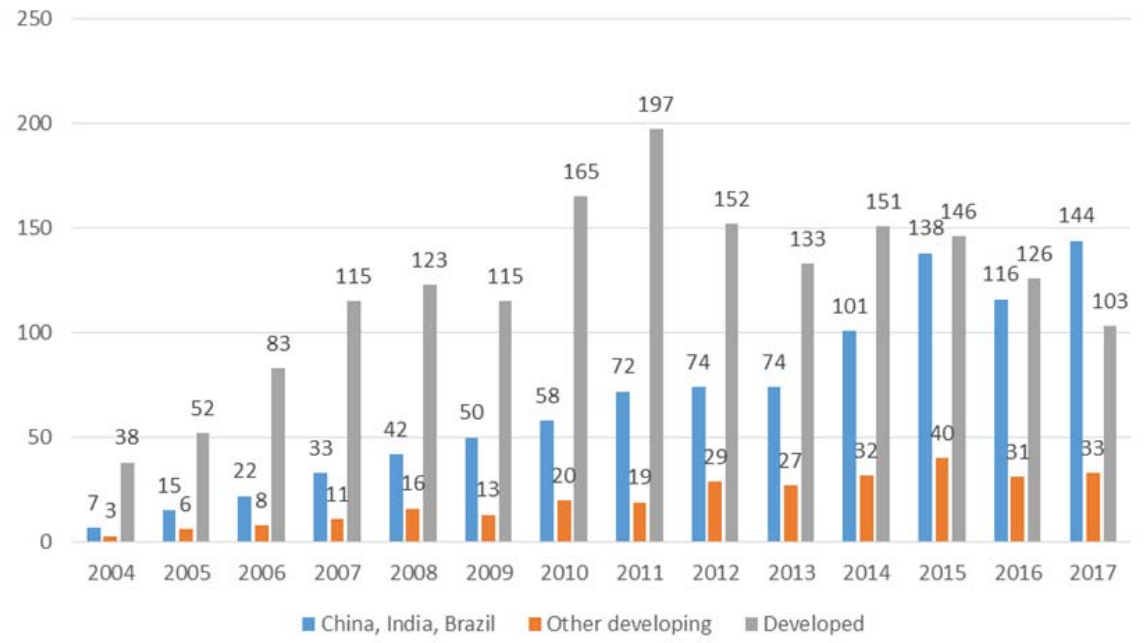

Source: UNEP, Bloomberg New Energy Finance

\footnotetext{
* New investment volume adjusts for re-invested equity. Total values include estimates for undisclosed deals. Developed volumes are based on OECD countries excluding Mexico, Chile, and Turkey. Details can be found at the following internet address: http://fs-unep-centre.org/sites/default/files/publications/gtr2018v2.pdf
} 
For the past two decades, a strong interest has emerged in favor of the integration of renewable energy sources in the energy and electricity mix, both in order to ensure energy security within the framework of energy transition policies and to address climate change consequences. Transitioning toward renewable energy sources seems all the more relevant because they allow the state to earn double dividends, as their diffusion actually reduces the volume of imported fossil energy (Criqui and Mima, 2012). For instance, in France the 2015 law on energy transition imposes a $30 \%$ diminution objective in the consumption of fossil energy. This would in turn lead to a $30 \%$ decrease in the country's energy dependence (given that France imports $99.9 \%$ of its fossil energy), induce a decrease in commercial deficit (and thus, of their financing), and could disrupt certain geopolitical balances or relationships with other importing countries. In order to assess relevant energy policy in this context, governments and states are leading the energy transition scenario, based on different tools such as model, storytelling or expert-based study.

One of the key questions raised by these foresight exercises concerns the evolution of the electricity supply and the conditions for integrating a growing share of variable renewable energy sources (RES) into power networks. This gradual increase must indeed take into account several factors: costs of the different technologies (wind, solar, etc.), public policies supporting variable RES, constraints due to the intermittency of these resources, productions in the network, regulation and political body expectations and evolutions, etc. All society stakeholders (state, company, consumer, non-governmental organizations) are now concerned by these various challenges and the multiple actions undertaken by politicians, citizens' associations, businesses and other institutional and non-institutional actors have led research whether public or private - to work on the concrete, technical, social or political impacts of the evolution of our energy systems. Both governments and citizens are nowadays associating 
the fight against pollution and climate change with the development of renewable energy sources.

The profusion of scientific research along with the numerous reports issued by government agencies reflect the interest and the concern of politics and society on this topic. The number of research papers or studies on the integration of variable RES into power networks has grown drastically since the beginning of the 2000s. In these numerous works, hypotheses differ depending on the space and timescale which are studied. The technical and complex aspect of the topic combined with its social and political offshoot often make it difficult to develop a global and synthetic approach to the research carried in this domain. This paper seeks to provide this global synthesis, through a bibliometric and bibliographic approach combined with a survey among actors of the energy research field and especially modelers.

\section{Methodology}

This article is based on a bibliometric study of the Scopus ${ }^{1}$ database on the topic of the integration of variable RES along with a review of the analysis of different government or regulation body reports on this topic. To confront the bibliometric and statistical results of the current and prospective research trends, an online survey was proposed to the researchers of the domain between June and July 2017.

\subsection{Bibliometrics : Recent state of the art}

Bibliometric analyses are used to explore the research trends and the evolution of researchers' interests in a field. Studying recently published research (2015-2018) we analyzed papers in the field of energy and environment that explicitly referred to the use of bibliometric analysis

\footnotetext{
${ }^{1}$ Scopus is the database of academic journal articles and other peer-reviewed publications related to the Elsevier publisher. It covers about 55 million entries.
} 
(Han et al., 2014; Wei et al., 2015; Chen et al., 2016; Gao et al., 2016; Yu et al., 2016; Zhang et al., 2016; Wang et al., 2017; Merigo and Yang, 2017; Zhang et al., 2017; Geng et al. 2017; Chen et al., 2017; Geng et al., 2017; Fabianne de Paulo and Silveira Porto, 2017; AleixandreBenavent, et al., 2018; Mao et al., 2018; Tiana et al., 2018). An analytic table of the different papers, their scope and the keywords and methods they use is provided in the appendix. These papers address different topics related to various energy questions: greenhouse gas emissions or climate policy assessment (Geng et al., 2017; Li and Zhao, 2015; Tiana et al., 2018; Wei et al., 2015); low carbon development or technology development (Gao et al., 2016; Fabianne de Paulo and Silveira Porto, 2017; Han et al., 2014; Yu et al., 2016; Wang et al., 2017a; Wang et al., 2017b;); carbon tax (Zhang et al., 2016); water footprint (Zhang et al., 2017); deforestation or biomass issues (Aleixandre-Benavent, et al., 2018; Mao et al., 2018) or life cycle assessment (Geng et al., 2017). The two most common methods used are content analysis and citation analysis. Content analysis uses either keyword analysis, which provides stats on the frequency in the literature of some chosen concepts, methods, technical terms, etc., or co-word analysis that searches for the strength of relations between words and by mapping them thus identifies relations and interactions between topics and emerging research trends (Wang et al., 2017). Citation analysis maps the relations between the different parts of the literature - mainly who cites whom - and thus identifies core literature, papers, journals, countries, authors, etc. (Gao et al., 2016). Social network analysis (SNA) using software such as Bibexcel and Gephii, which are the most popular currently in use (five papers over 17 studied mention using both software types), derives from citation analysis and assesses the relation between researchers, institutions or countries exploring the links between them (copublication, partnerships, co-affiliation, etc.). In most cases, results come out as clusters of relations between concepts, authors, research institutions, etc. Papers usually choose between the two approaches, focusing either on the content of the literature through keyword analysis 
or studying the publication dynamics, assessing production or collaboration status. Here, we combined the two methods, as we needed both a mapping of production and collaboration statistics to link it to the energy policy led by different countries or regions, and an assessment of the trending research topics to build our online survey.

The most commonly used database is the Web of Science (six papers out of 17 mention using it), which includes Science Citation Index Expanded ${ }^{2}$ (seven papers out of the 17 studied mention using it). Finally 13 papers out of 17 mention the Web of Science Core Collection databases. It is the most diversified database covering various scientific topics (from agriculture to medicine and economics). It encompasses more than 20,000 journals and 1.4 million cited references. ${ }^{3}$

\subsection{Bibliometric study and on-line survey}

In this paper we use both content analysis and SNA along with some other indicators such as geographic scope and time frame. The list of papers included in the bibliometric study is provided in the appendix along with elements used for the analysis. The online survey was designed and conducted after the first results of the bibliometric analysis were obtained. It aimed at identifying further research issues and prospective trends, and gathering some verbatim on the current research state of play. It was carried through a Google Form and contained three different parts: 1 . Semi-directive questions regarding variable RES integration (most important conditions, players, technology need, etc.); 2. Open questions regarding research trends, remaining problems, and suggested solutions. 3. Questions addressed to economic modelers about their models, tools, and issues. The respondents were asked to

\footnotetext{
${ }^{2}$ The web of science consists of 7 databases the Conference Proceedings Citation Index, the Science Citation Index Expanded, the Social Sciences Citation Index, the Arts \& Humanities Citation Index, the Index Chemicus, the Current Chemical Reactions and the Book Citation Index.

${ }^{3}$ https://clarivate.com/products/web-of-science/web-science-form/web-science-core-collection/
} 
provide their name, email, and affiliation, and the results were aggregated to ensure the confidentiality of answers. The survey was sent first and foremost to the corresponding authors of the papers who had previously collected for the bibliometric study. We identified them as the main research stakeholders ${ }^{4}$ able to provide insights on the ongoing research trends regarding the topic. We also handed out the survey to some European industrial (TSOs, electricity providers, smart grids start-ups), institutional (World Bank, IEA, OECD) and nongovernmental organizations (NGO) actors. They were all involved at a certain level in research activities regarding the integration of renewable energy sources into power networks. We thus contacted 120 researchers and actors involved in research dynamics of the domain and 60 of them have answered the survey. Researchers came mostly from the European Union but also from the United States (US), Australia, South-Africa, and China. Other actors involved in research dynamics (industrial, institutional, and NGO actors) represent less than $10 \%$ of the answers, they all came from the European Union. The lists of questions and of respondents' institutions are available in the appendix.

Through both the bibliometric and the survey approach, the objectives of this study were, first, to identify key players among states and research institutions or nodes of collaboration; second, to identify key concepts, how they are linked together, and what types of scenarios and models they bring; and third, to identify potential research leads on the topic.

\footnotetext{
${ }^{4}$ The stakeholders in this case are the researchers working on the integration of variable renewable energy sources and we identified them mostly through their publications (as the corresponding authors of the articles analyzed in the bibliometric study) or research activities in industrial, institutional, or non-governmental organizations. We considered they were the current research leaders on the topic and would thus provide the best information on the ongoing trends regarding this topic. We identified through the process mentioned above around 120 people to whom we could send our survey and 60 of them have answered. The optimal sample size would of course have been to get 120 replies, but some people chose not to reply or replied they had change their research interests and did not feel comfortable enough with the subject to answer the survey.
} 


\subsection{Dynamics of publication on variable renewable energy (VRE)}

Since 1970, according to the Scopus database, around 10,000 papers (articles, conference papers or other peer-reviewed documents) have been published on the integration of variable renewable energy (VRE) integration into power networks (Figure 2). Eighty percent of this scientific literature has been published since 2010, which demonstrates the growing academic interest in this topic. Among this wide database we have led bibliometric analyses, using the text-mining software Intellixir. ${ }^{5}$ Through statistics and a graph of links, they show the relations between the concepts used in the publications and between the authors and institutions that produce them. A sub-base has been made in the literature dealing with the scenario modeling of the energy transition and the integration of variable RES into power networks. Around 150 peer-reviewed documents have been published on the topic, all within the last 10 years.

Figure 2: Number of publications related to integration of variable renewable energies (VRE) into power networks per year

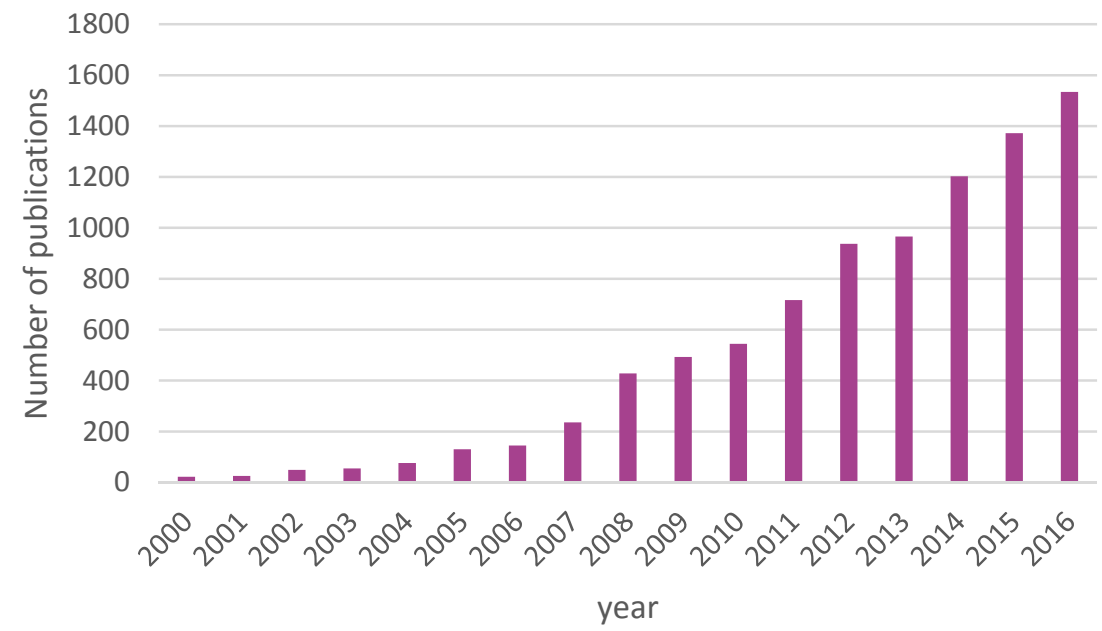

Source: Scopus/Intellixir

\footnotetext{
${ }^{5}$ Intellixir is a text mining tool for statistical and bibliometric analysis of the articles found in the Scopus database (concepts used, origin of publications, links of collaborations between authors and institutions, etc.).
} 


\section{Publication dynamics: Mapping of academic collaborations and geographic trends}

\subsection{Variable RES integration: States, research centers and main colaborations}

The main publisher on the integration of variable RES into power networks remains the US with a steady level publication of around 250 peer-reviewed documents per year since 2012 (Figure 3). They have held this position since international research took an interest in the subject. The American rate of publication was the first to take off and started growing between 2007 and 2008. China began publishing later and has been progressively catching up with the US trend in recent years. It gained second position over Germany in 2016, almost doubling its number of publications compared to 2015 and reaching around 200 papers per year.

Figure 3: Number of publications on the integration of variable RES into power network per country

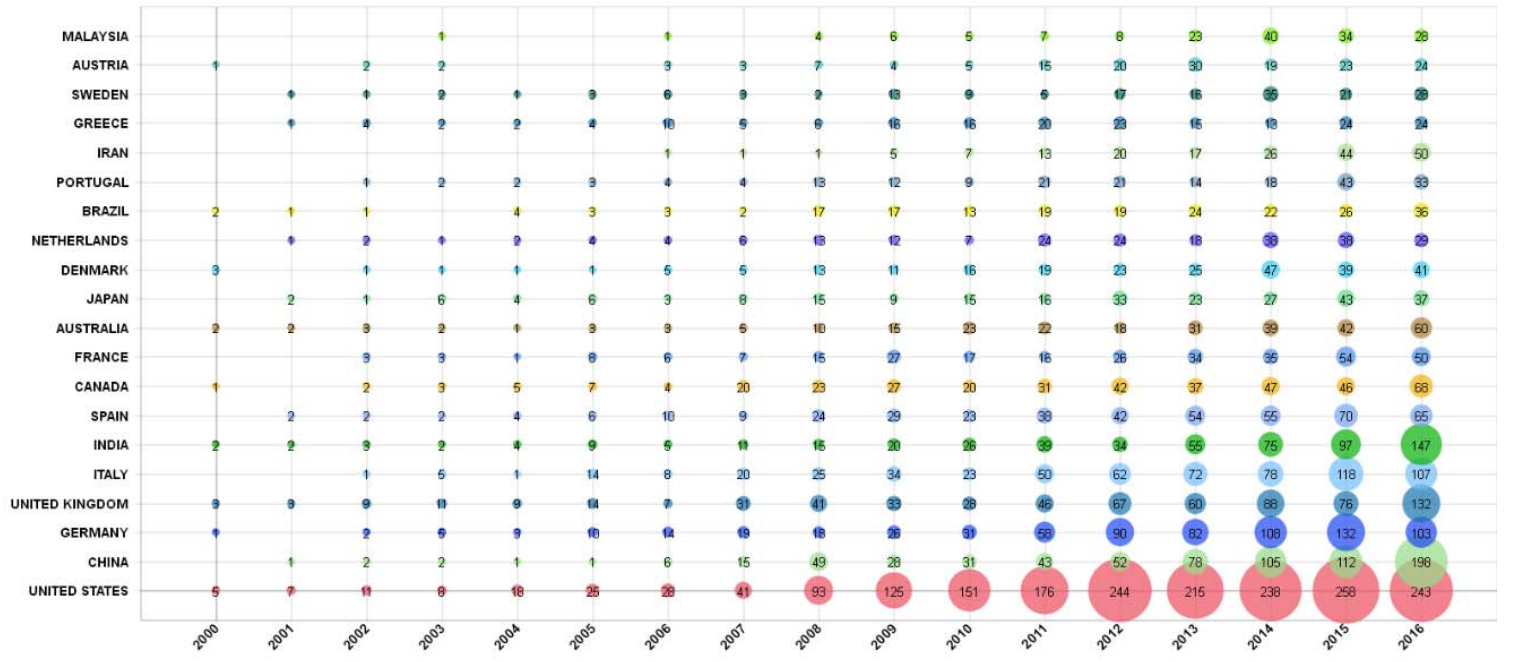

Source: Scopus/Intellixir

Germany, the United Kingdom (UK), Italy, and India form a second group of countries with around half the level of American publications (roughly 100 papers per year). For these countries the rate of publication took off a bit later, around 2012. The third group of countries publishing in the same domain release around 50 papers per year and is formed by a group of 
European countries (Spain, France, Denmark, the Netherlands, and Portugal) alongside Canada, Australia, Japan, Brazil, and Iran. The rate of publication does not show any correlation with a specific factor such as research and development (R\&D) expenses on Gross domestic product (GDP) or researcher per million inhabitants (Table 1) nor with the level of variable RES on the electricity mix (Figure 4).

Table 1: Statistics on R\&D, GDP, publication and researcher per country

\begin{tabular}{|l|c|c|c|c|c|c|}
\hline & \multicolumn{2}{|c|}{$\begin{array}{c}\text { Share of R\&D on } \\
\text { GDP (in\%) }\end{array}$} & $\begin{array}{c}\text { GDP (Billion } \\
\text { \$Us) }\end{array}$ & $\begin{array}{c}\text { Number of } \\
\text { publications } \\
\text { in 2016 }\end{array}$ & $\begin{array}{c}\text { Researcher } \\
\text { per million } \\
\text { inhabitant }\end{array}$ & $\begin{array}{c}\text { Publication } \\
\text { per R\&D } \\
\text { point }\end{array}$ \\
\hline United-States & 1995 & $2015^{*}$ & 2016 & 2016 & 2015 & 2015 \\
\hline China & 2.44 & 2.79 & 18569.1 & 243 & 4231 & 87 \\
\hline India & 0.56 & 2.07 & 11199.1 & 198 & 1177 & 96 \\
\hline United-Kingdom & 1.61 & 1.7 & 2618.3 & 132 & 4471 & 78 \\
\hline Italia & 0.95 & 1.33 & 1849.9 & 107 & 2018 & 80 \\
\hline Germany & 2.13 & 2.88 & 3466.7 & 103 & 4431 & 36 \\
\hline Canada & 1.61 & 1.61 & 1529.7 & 68 & 4518 & 42 \\
\hline Spain & 0.79 & 1.22 & 1232 & 65 & 2655 & 53 \\
\hline Australia & 1.66 & 2.2 & 1204.6 & 60 & NA & 27 \\
\hline France & 2.21 & 2.23 & 2465.4 & 50 & 4168 & 22 \\
\hline Iran & 0.5 & 0.32 & 393.4 & 50 & 738 & 156 \\
\hline Denmark & 1.8 & 3.01 & 306.1 & 41 & 7484 & 14 \\
\hline Japan & 2.69 & 3.28 & 4939.3 & 37 & 5231 & 11 \\
\hline Brazil & 1 & 1.16 & 1796.1 & 36 & 698 & 31 \\
\hline Portugal & 0.55 & 1.28 & 204.5 & 33 & 3824 & 26 \\
\hline Netherland & 1.86 & 2.01 & 770.8 & 29 & 4548 & 14 \\
\hline Sweden & $\mathrm{NA}$ & 3.26 & 510.9 & 28 & 7022 & 9 \\
\hline Malaysia & 0.22 & 1.3 & 296.3 & 28 & 2261 & 22 \\
\hline Greece & $\mathrm{NA}$ & 0.96 & 194.5 & 24 & 3201 & 25 \\
\hline Austria & 1.59 & 3.07 & 386.4 & 24 & 4955 & 8 \\
\hline NA:Not & & & & & 216 & 233 \\
\hline
\end{tabular}

NA: Not available

*Or 2013 or 2014 if R\&D Figures were not available for 2015

Sources: Scopus, World bank 
Figure 4: Number of publications and \% of variable RES in the electricity production in 2016

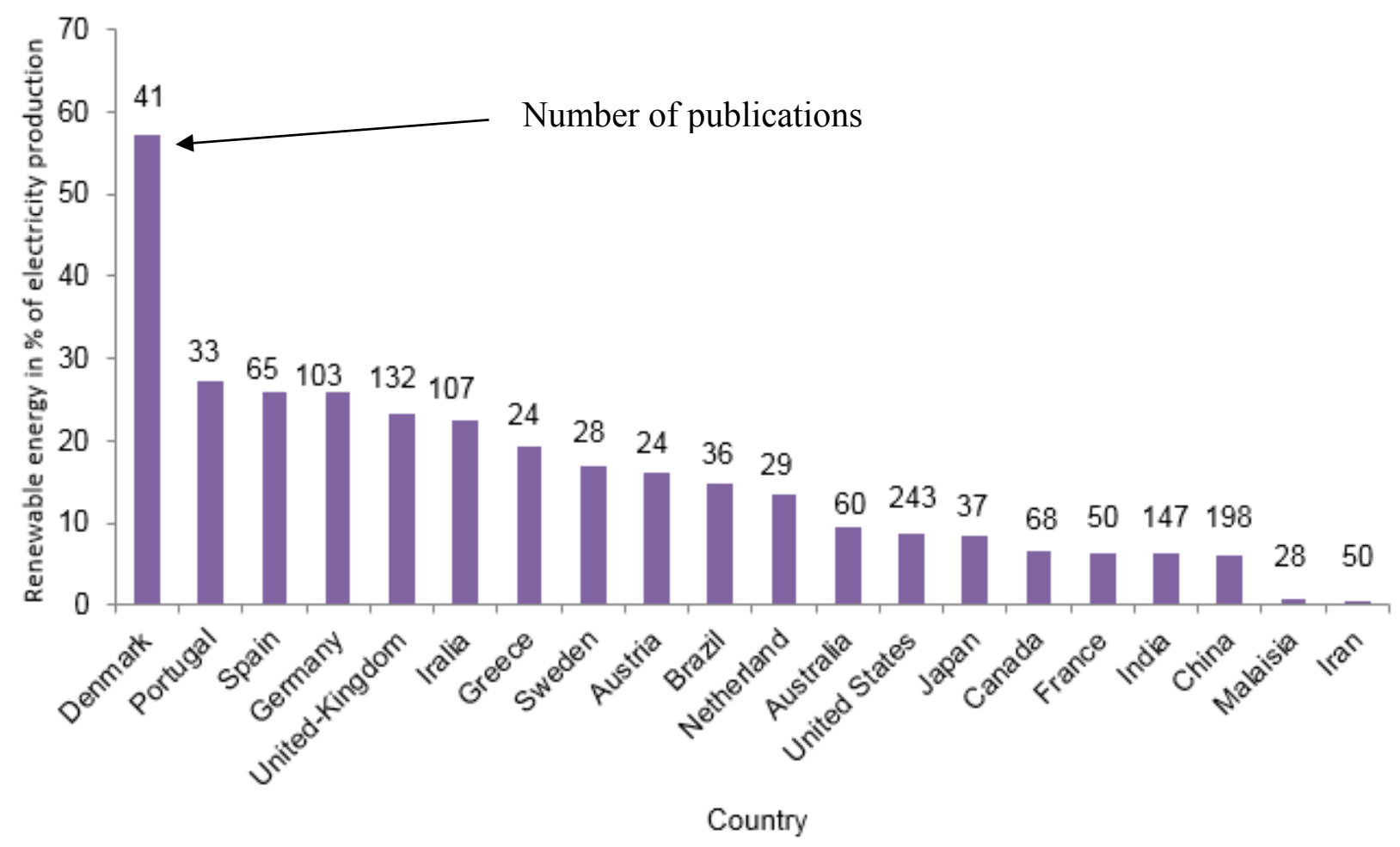

Source: Enerdata, Scopus

The ranking of research institutions according to the number of publications on the topic shows a geography that is a little different. If the American and Chinese research institution dominate the top 10 publishers, the research institution that has been publishing the most since 2013 is the University of Beijing (in 2016 it represented around 25\% of the Chinese publications in the domain). It is followed by the National Energy Technology Laboratory (NETL) of the US Department of Energy ${ }^{6}$ which in 2016 published two times less than the University of Beijing (Figure 5). The third publisher, the University of Tehran (Iran) has shown a steady growth of publications over the last three years and is catching up to the NETL. In contrast, the European publications appear far more scattered: the first European research institution, the University of Aalborg (Denmark) appears in $7^{\text {th }}$ position followed by

\footnotetext{
${ }^{6}$ https://www.energy.gov/
} 
the University of Athens (Greece) in $9^{\text {th }}$ position, the University of Madrid (Spain) $13^{\text {th }}$, and the French National Center for Scientific Research (CNRS), $14^{\text {th }}$. The European research thus appears more distributed among a variety of research centers compared to the other publishing countries.

Figure 5: Number of publications on the integration of variable RES into power network per research institutions (2000-2016)

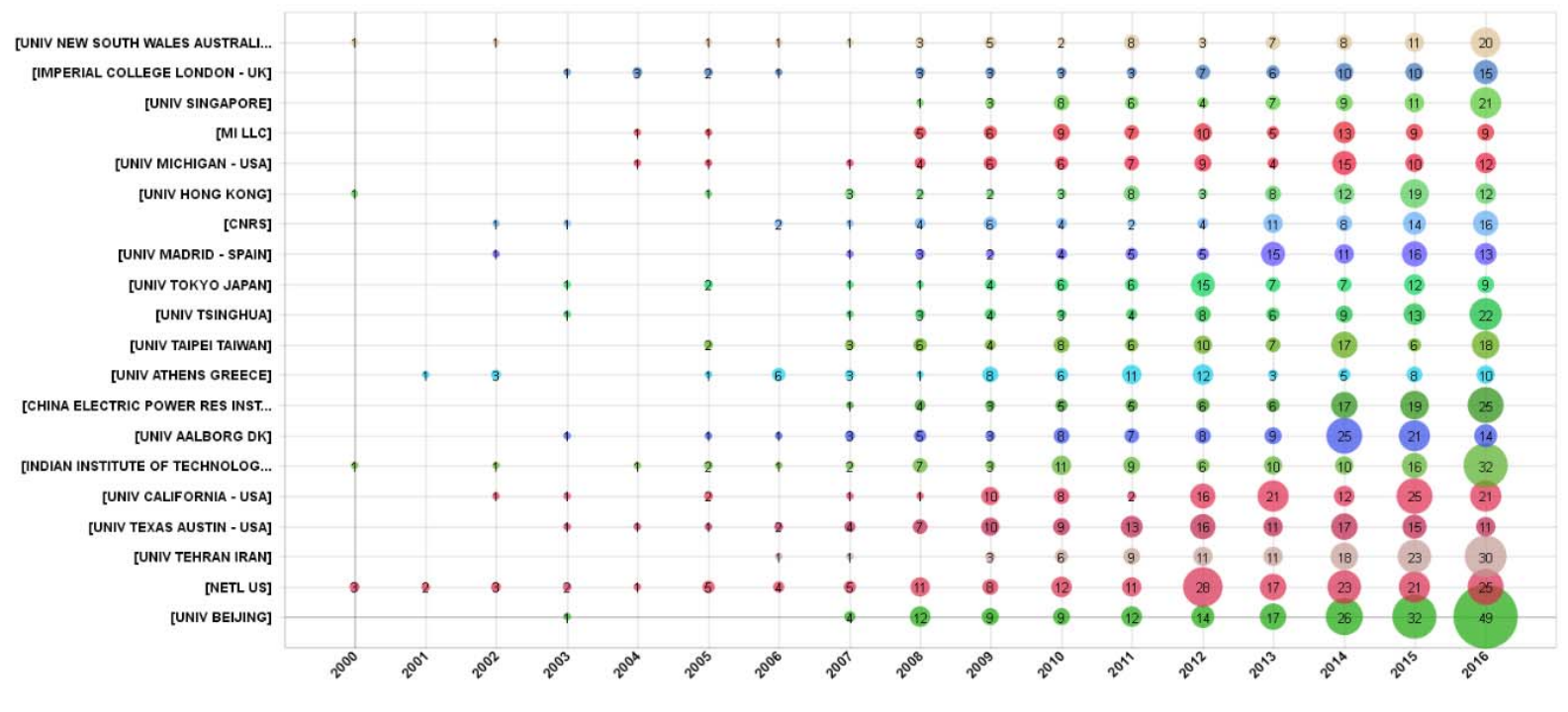

Source: Scopus/Intellixir

Because the topic of variable RES into a power network is wide, multidisciplinary, and very complex to tackle, and because it is of interest to the entire international research community, collaborations between researchers and between research institutions are essential for solving problems and the questions they bring about. We have approached and mapped the collaborative dimension of international research on the integration of variable RES into power networks through the analysis of co-publications.

From 1970 to 2017, the US polarized the great majority of international collaborations (Figure 6). A second cluster of exchanges within the European Union (EU) is also visible. Member states collaborate between themselves but, apart from the UK and Germany, they have few links with countries outside of the EU. Other states outside the EU where the level of publication is high (India, Japan, Canada, Iran, Brazil, China or Australia) publish in quite an 
islanded manner. They all have collaboration links with the US but collaborate very little between them or with the EU cluster.

Figure 6: Collaboration network among the different countries

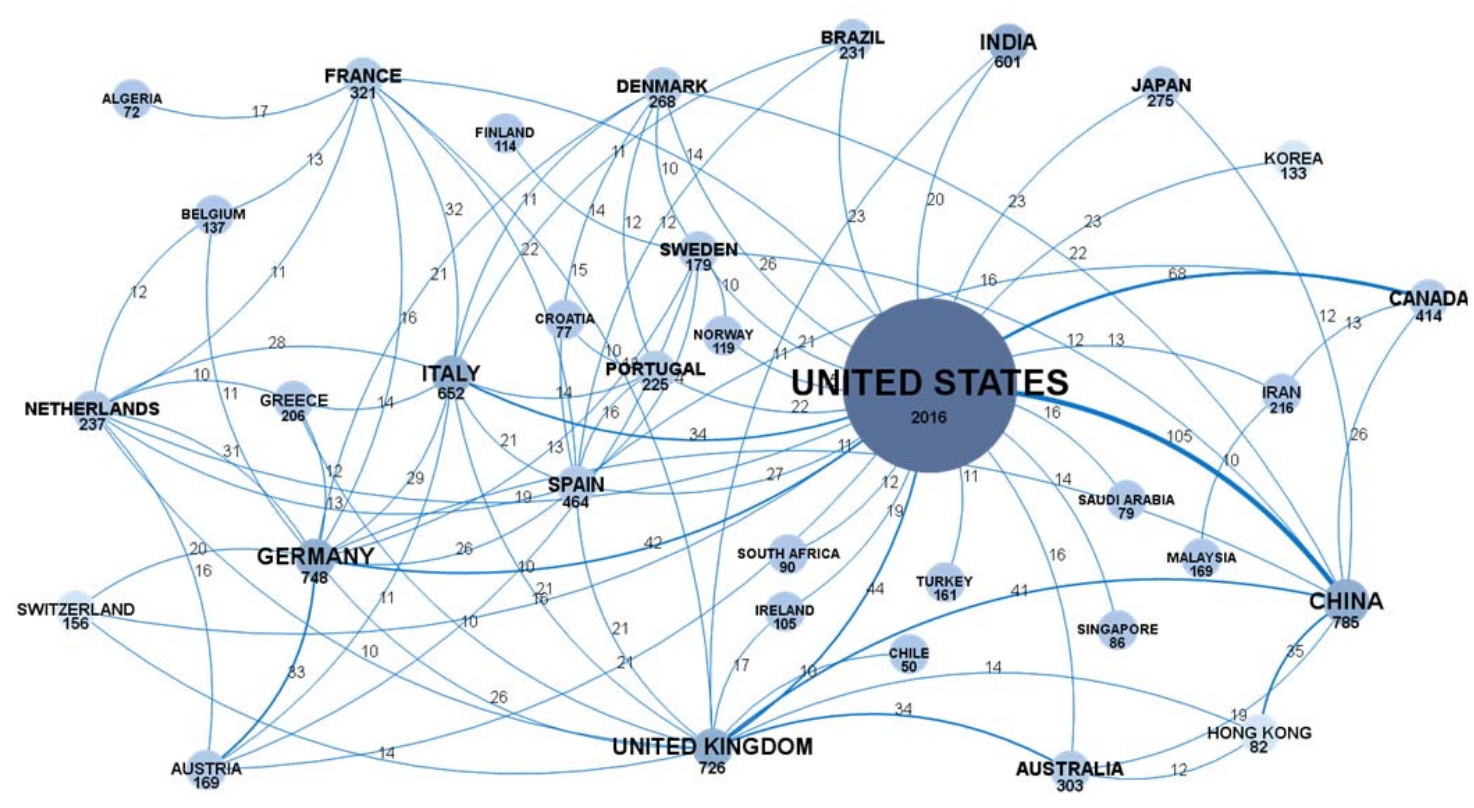

Source: Scopus/Intellixir

* Numbers represent the number of publications by country and jointly written by two different countries. Numbers on hubs correspond to the publications by country and numbers on spokes correspond to the publications jointly written by the two different countries at each end of the spoke.

Co-publication relations between research institutions give a closer insight into how research on the topic is structured. The large majority of collaboration relations are polarized at the national level around one lead research center that collaborates with a hinterland of smaller publishers within the same country. This is the case for the US with the NETL, for China with Beijing University (Figure 7), for Japan with Tokyo University (Figure 9), for Denmark with Aalborg University, for Greece with Athens University, for South Korea with Seoul University, for the Balkan states with Zagreb University, for the Benelux countries with the Catholic University of Leuven, for Italy with the universities of Naples and Rome or for France with the CNRS. 
Some clusters escape this general rule. The Australian and Taiwan research centers present quite a meshed and balanced network of collaborations with no major polarity. Two northEuropean clusters of collaboration with no leading institution can also be identified (Figure 8), dominated by German and UK research centers associated with Scandinavian, Benelux, and some American teams. It seems quite significant that the two leading European countries in terms of publications (namely Germany and the UK) are also the ones that collaborate the most and the ones with the most distributed and international (though dominated by European partnerships) network of co-authorship.

Figure 7: Chinese research cluster on variable RES

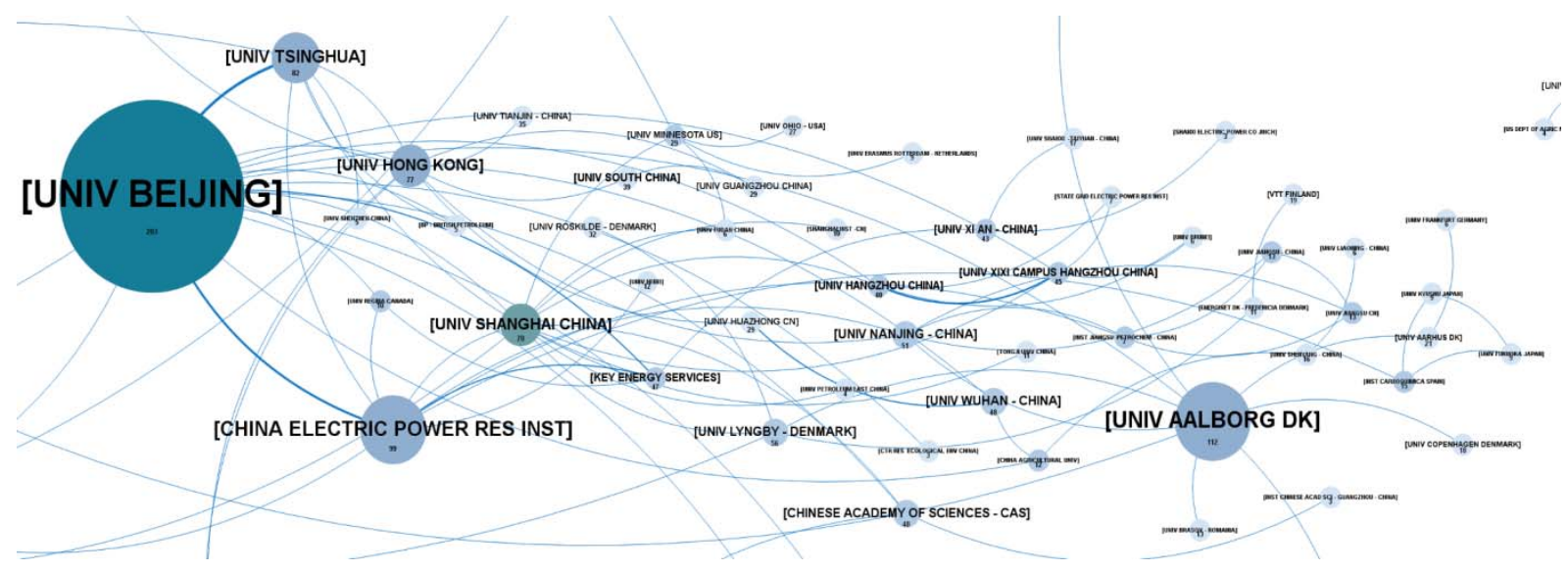

Source: Scopus/Intellixir

* Numbers represent the number of publications by country and jointly written by two different countries. Numbers on hubs correspond to the publications by country and numbers on spokes correspond to the publications jointly written by the two different countries at each end of the spoke. 
Figure 8 : European research cluster on variable RES

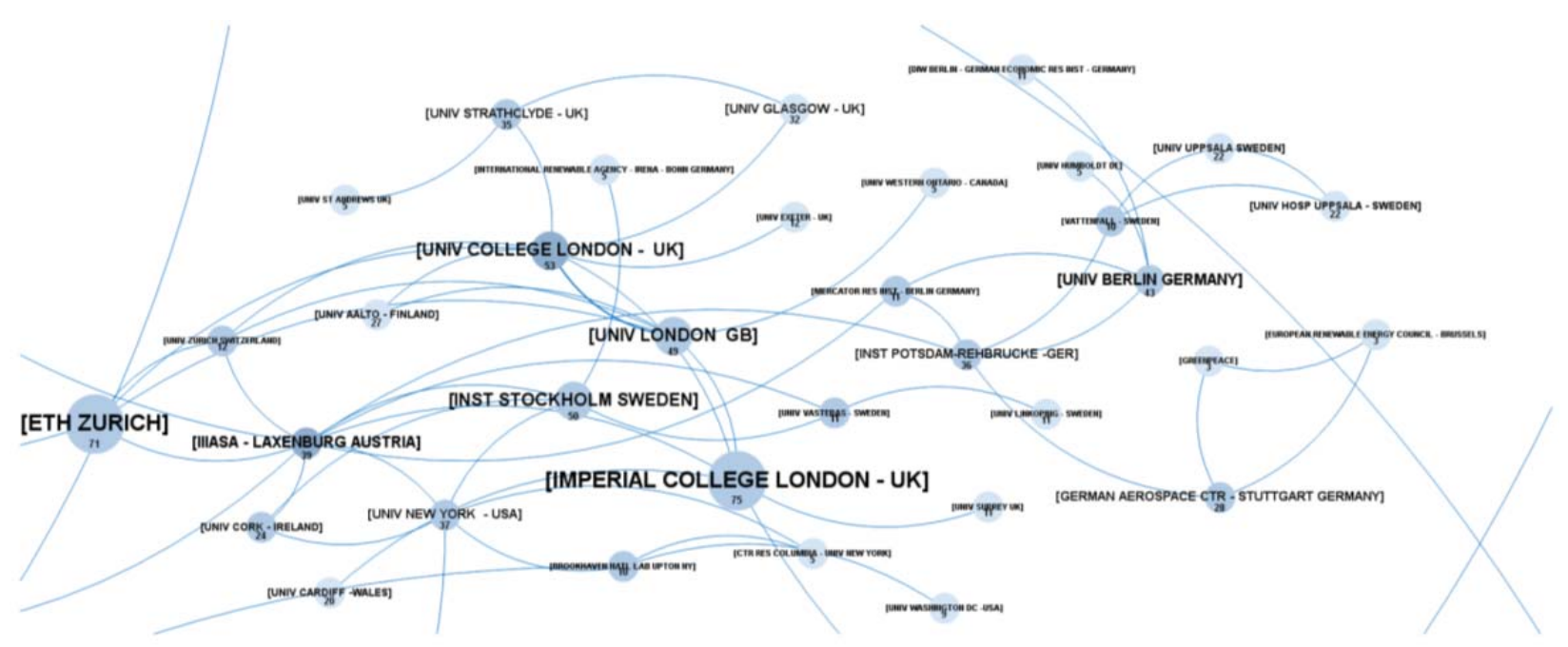

Source: Scopus/Intellixir

* Numbers represent the number of publications by country and jointly written by two different countries. Numbers on hubs correspond to the publications by country and numbers on spokes correspond to the publications jointly written by the two different countries at each end of the spoke.

Figure 9 : Japanese research cluster on variable RES

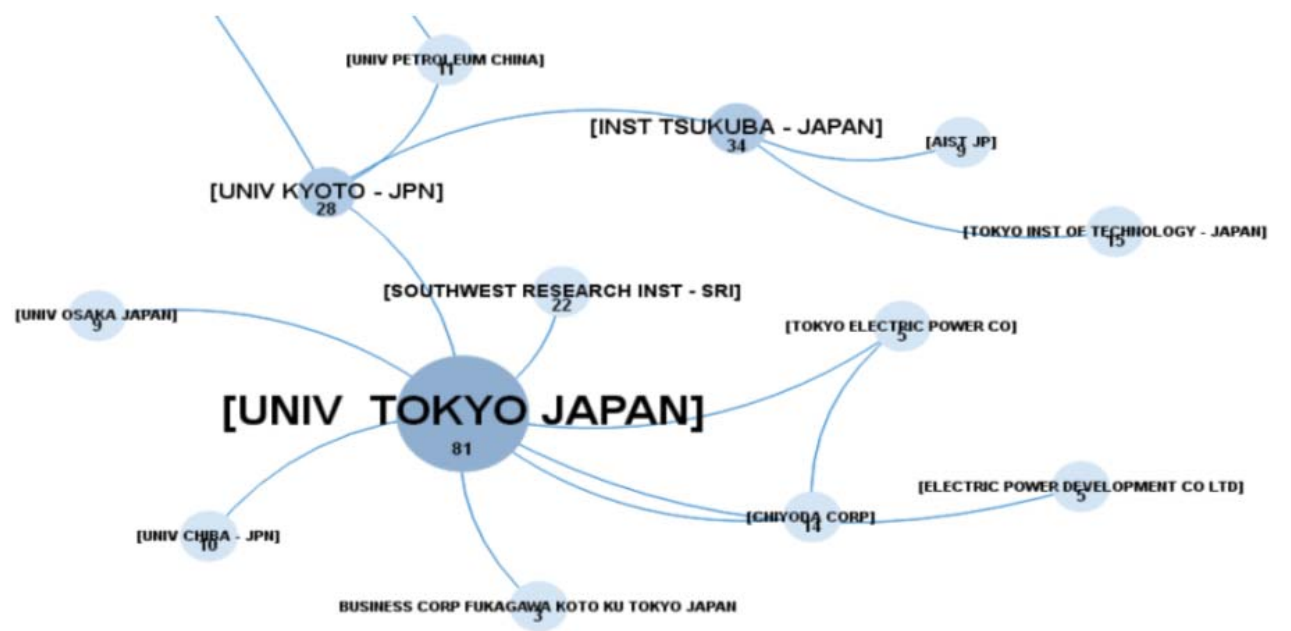

Source: Scopus/Intellixir

* Numbers represent the number of publications by country and jointly written by two different countries. Numbers on hubs correspond to the publications by country and numbers on spokes correspond to the publications jointly written by the two different countries at each end of the spoke.

If we focus on the scenario building publications, the cartography seems a little different.

Collaborations seem to be driven more by geographic proximity, which could be explained by the fact that most of the integration scenario are made at a national or macro-regional level. 
The most important clusters of collaboration are European. North-American teams work together and one cluster breaks this general rule and brings together teams from China, Japan, Germany, Sweden, and the UK.

\subsection{The most influential actors for a fast integration of variable RES}

The problem with the integration of high levels of variable RES into power networks is not just a technical one or an economic one. Because of the impacts it can have on markets, consumption behavior, supply policy for states, and society at large, it goes beyond disciplinary barriers and calls for a multidisciplinary and multi-actor approach. Ninety percent of our survey respondents consider themselves to be researchers. They were contacted and asked to fill out the survey as they are the corresponding authors of the papers considered in the two sub-bases we have built from the Scopus database on RES integration scenarios. Among the $10 \%$ remaining respondents are some European policymakers, NGO members, market analysts or industry-oriented profiles. As they provided few verbatim and were not enough of a consistent group we chose not to consider them separately from the rest of the respondents. We asked the respondents to choose and rank the actors whose implication they consider the most important for a fast and smooth integration of variable RES into power networks (Figure 10). 
Figure 10 : Most influential actors for a fast integration of VRE into power networks

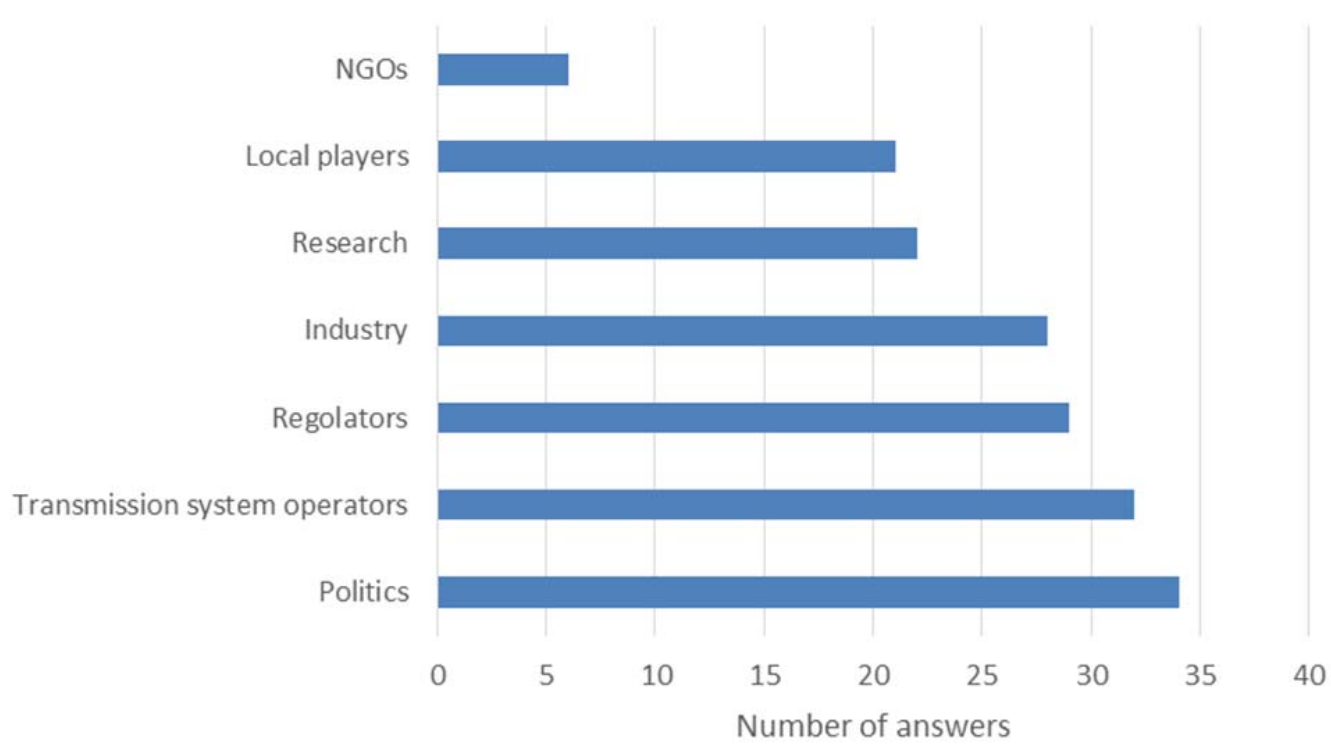

Source: ANCRE Survey

\footnotetext{
* This figure can be read as follow: 34 respondents consider politics as the most influential actors for a fast integration of VRE into power networks.
}

Politics come first in the ranking of the most important players that have to be involved in the process of variable RES integration, which would call for a deeper study of policy impact from the research community. Transmission system operators (TSO), regulators, and industry are mentioned immediately after politics: they represent the technical and economic part of the issue. Then comes research, along with local actors, which would make a case for the idea that this integration is not necessarily a matter of technological breakthrough brought about by new research but more a matter of political, economic, and industrial choices. Many of the respondents commented with the idea that communication and strong cooperation between all the above-mentioned actors would be necessary to allow high rates of integration.

\section{Scenario and modeling tools}

Policymakers are most interested in a few key questions: the delimitation of the amount of variable RES it would be possible to include in the power networks without threatening their 
stability, what the cost would be for society, and how long it would take to implement. We focus in this part on both scenario building and modeling tools in the scientific literature, as they are the main aspects used by the research community to address these questions.

\section{1 key concepts}

The bibliometric analysis allows for the mapping of key concepts used in scientific literature on the integration of variable RES into power networks and gives some insight into how they are linked together. One of the main results of this analysis shows the importance of scenario building and modeling (Figure 11).

Figure 11: Map of the main concepts used in the papers published on VRES integration

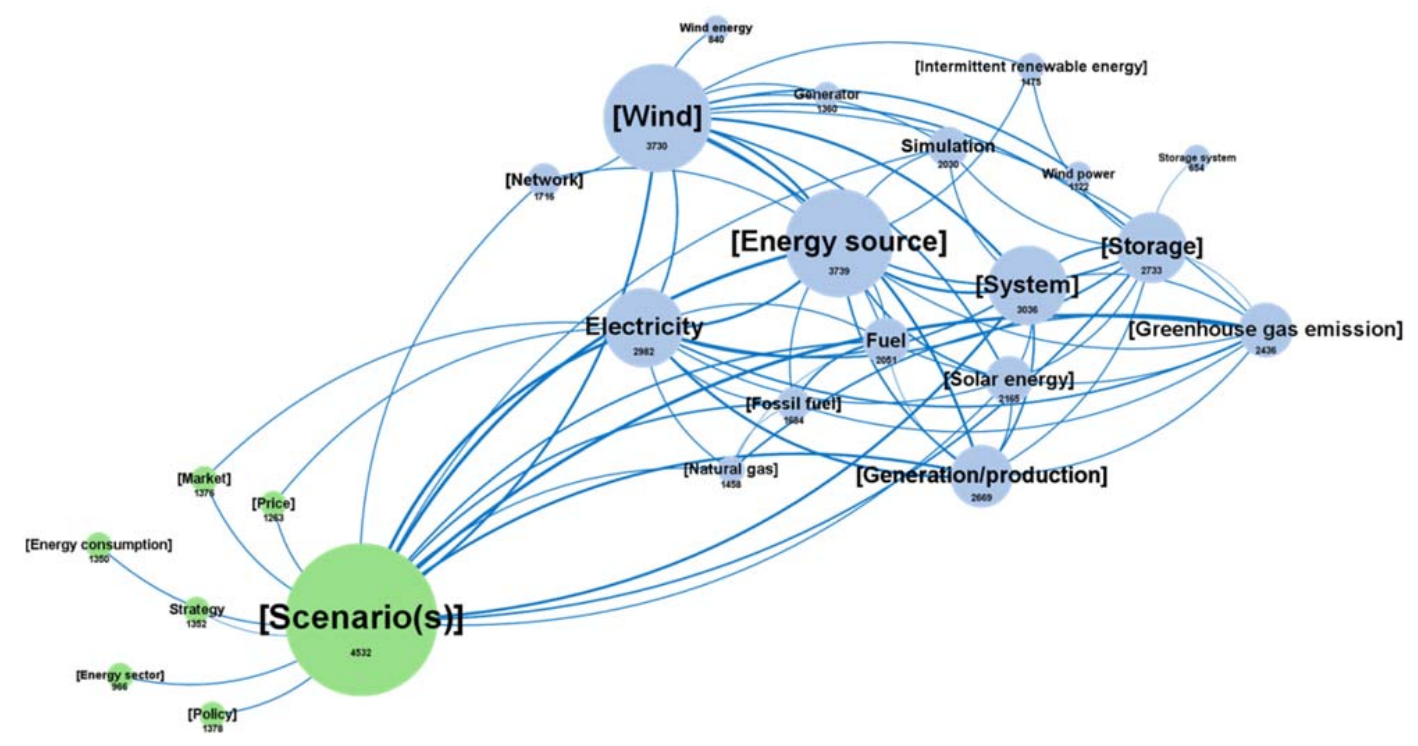

Source: Scopus/Intellixir

Because of this importance of scenario building in the literature and also because it is one of the main interests policymakers have in current research, we focus here on the different scenario types: how they are modeled and how scientific community views their possible evolution. 


\subsection{Time horizon.}

2050 seems to be the major reference for scenario projections and is used by around two thirds of the papers. However, half of the papers that model the integration of $100 \%$ of variable RES into the power network they study choose not to develop their scenario within a time frame, whereas only $20 \%$ of scenarios that postulate lower levels of integration do so. This difference of projection in time might be explained by a political aspect underlying the different types of scenarios. One hundred percent integration scenarios often consider the integration of RES as a goal per se and try to demonstrate that it will be possible to reach it eventually, whereas other scenarios with lower levels of integration go the other direction and tend to test practical options that are more or less immediately applicable. In both cases, the choice of 2050 as a target remains political as a "mid-term," "mid-century" commonly accepted time reference for energy and environment policymaking.

\subsection{Scale}

When asked about the most accurate scale for the integration of variable RES into power networks most of the respondent researchers put forward the local and regional level. Even though they do not discriminate strongly between the different scales and most of them comment on their answer, saying cross-scale dynamics are essential to the process, the result is interesting when compared to the statistics of publication. More than half of the published papers that propose a scenario focus on the national level. The second most studied scale is the macro region ( $15 \%$ of the papers), and local and regional levels both make respectively less than $10 \%$ of the published papers. This discrepancy between the scales that are deemed more accurate to study and the ones that are effectively studied, as well as the predominance of scenarios at the national level may be the result of policymakers' interest (and financing) for studies and scenarios at their own level of action, which is often a national one. 


\subsection{Geographic dimension}

The geographic span of scenarios on the integration of variable RES into power networks is rather limited. Three poles are particularly studied: the US, the EU, and Asian (mainly China, South Korea, and Japan). Australia also appears in the 100\% RES integration scenarios. Most of the papers published come from the same areas and researchers tend to publish in the areas where they work. However, the lack of research on developing areas where the electrification process is scarce, ongoing or structured very differently from the large and highly meshed networks of industrialized countries, seems problematic from a global and long-term perspective. The World Energy Council (WEC) foresees that the African demand for electricity will triple between 2015 and 2025 but research scenarios show a remarkably low interest for this continent even though it might be a game changer from a global perspective.

\subsection{Model types}

Respondent modelers used a large variety of models (Figure 12). The respondent modelers cited among others the following models: ${ }^{7}$ Antares, ${ }^{8}$ Dispa-SET, ${ }^{9}$ EnergyPLAN,${ }^{10}$ H2RES, ${ }^{11}$ Imaclim-R, ${ }^{12}$ and In-house model based on GAMS, ${ }^{13}$ LEAP, ${ }^{14}$ LUT Energy System Model, ${ }^{15}$

\footnotetext{
${ }^{7}$ All the footnotes related to the model are based on the Model presentation webpage.

8 ANTARES is a Monte-Carlo software for power systems analysis (https://antares.rte-france.com/wpcontent/uploads/2016/09/160913-Antares_public_short.pdf)

${ }^{9}$ The Dispa-SET model is an open-source unit commitment and optimal dispatch model focused on the balancing and flexibility problems in European grids.( http://www.dispaset.eu/en/latest/)

${ }^{10}$ EnergyPLAN simulates the operation of national energy systems on an hourly basis, including the electricity, heating, cooling, industry, and transport sectors. It is developed and maintained by the Sustainable Energy Planning Research Group at Aalborg University, Denmark. (http://www.energyplan.eu)

${ }^{11}$ H2RES is a balancing tool that simulates the integration of renewable energy into energy systems. The model is developed by the Instituto Superior Técnico, Lisbon and the Faculty of Mechanical Engineering and Naval Architecture at University of Zagreb, Croatia in 2000. (http://www.energyplan.eu/othertools/island/h2res/)

${ }^{12}$ IMACLIM-R is a multi-sector multi-region dynamic recursive growth model (12 sectors and 12 regions). It provides a macroeconomic framework which analyzes the relations between the economy and energy sectors. (http://www2.centre-cired.fr/IMACLIM/Description-des-modeles-IMACLIM/IMACLIM-R/article/IMACLIM$\left.\frac{\mathrm{R}}{13}\right)$

${ }^{\frac{R}{13}}$ The General Algebraic Modeling System (GAMS) is a high-level modeling system for mathematical programming and optimization. (https://www.gams.com/products/introduction/).
} 
NEMO,${ }^{16}$ Plexos, ${ }^{17}$ OEMOF,${ }^{18}$ OSeMOSYS,${ }^{19}$ Poles,${ }^{20}$ Power Factory, ${ }^{21}$ Times for different countries, ${ }^{22}$ TIAM World. ${ }^{23}$

In our survey their comments mention four key elements for the future of variable RES integration modeling: (i) an integrated vision that would need to consider all the impacts without a "silos" approach; (ii) the need for a constant link between models and scenarios; (iii) a collaboration between energy system modelers and grid modelers is required; (iv) the challenge of flexibility, necessary for the integration of intermittence, need to be addressed.

${ }^{14}$ LEAP, the Long-range Energy Alternatives Planning System, is a widely-used software tool for energy policy analysis and climate change mitigation assessment developed at the Stockholm Environment Institute. (https://www.energycommunity.org/default.asp?action=introduction).

${ }^{15}$ The LUT-model is an hourly resolution model of the power generation system developed at the Lappeenranta University of Technology (LUT) in Finland (https:/www.lut.fi/web/en/school-of-energy-systems/modellingenergy-systems/studies).

16 The National Electricity Market Optimiser (NEMO) is a chronological dispatch model for testing and optimizing different portfolios of conventional and renewable electricity generation technologies. It was first developed by Ben Elliston in 2011 at the Centre for Energy and Environmental Markets, University of New South Wales. (https://nemo.ozlabs.org/)

${ }^{17}$ PLEXOS $®$ Integrated Energy Model (PLEXOS) is a tried-and-true simulation software that uses state-of-theart mathematical optimization combined with the latest data handling and visualization and distributed computing methods, to provide a high-performance, robust simulation system for electric power, water, and gas that is leading edge yet open and transparent. (https://energyexemplar.com/software/plexos-desktop-edition/).

${ }^{18}$ OEMOF is a modular open source framework to model energy supply systems. OEMOF addresses current and future challenges in energy system modeling by being cross-sectoral, multiregional, Time-Step-Flexible, and community driven (https://oemof.org/)

19 OSeMOSYS is an open source modeling system for long-run integrated assessment and energy planning. (http://www.osemosys.org/)

${ }^{20}$ Prospective Outlook on Long-term Energy Systems (POLES) is a world energy-economy partial equilibrium simulation model of the energy sector until 2050, with complete modeling from upstream production to final user demand and greenhouse gas emissions. POLES is used and developed by Enerdata in collaboration with the European Commission's JRC IPTS and University of Grenoble-CNRS (EDDEN laboratory). (https://www.enerdata.net/solutions/poles-model.html).

${ }^{21}$ PowerFactory combines extensive modeling capabilities with advanced solution algorithms, thereby providing the analyst with tools to undertake the full range of studies required for grid connection and grid impact analysis of wind parks, photovoltaic (PV) plants, and all other kinds of power park modules using renewable energy (https://www.irena.org/-

/media/Files/IRENA/Agency/Articles/2012/Jul/6_Koos_Theron.pdf?la=en\&hash=AAA89C654FEB87FD550E0 3F2AAFB9CEA7DEBC142).

${ }^{22}$ The TIMES (The Integrated MARKAL-EFOM System) model generator was developed as part of the IEAETSAP's methodology for energy scenarios to conduct in-depth energy and environmental analyses (Loulou et Labriet, 2008). The TIMES model generator combines two different, and complementary, approaches to modeling energy: a technical engineering approach and an economic approach. In a nutshell, TIMES is used for, "the exploration of possible energy futures based on contrasted scenarios" (Loulou et Goldstein, 2005). (https://iea-etsap.org/index.php/etsap-tools/model-generators/times).

${ }^{23}$ The TIMES Integrated Assessment Model (TIAM-WORLD) is a multi-regional and inter-temporal partial equilibrium model of the entire energy/emission system of the World, based on the TIMES paradigm (http://kanorstest1.kanlo.net/models/tiam-world). 
Figure 12: Types of model used

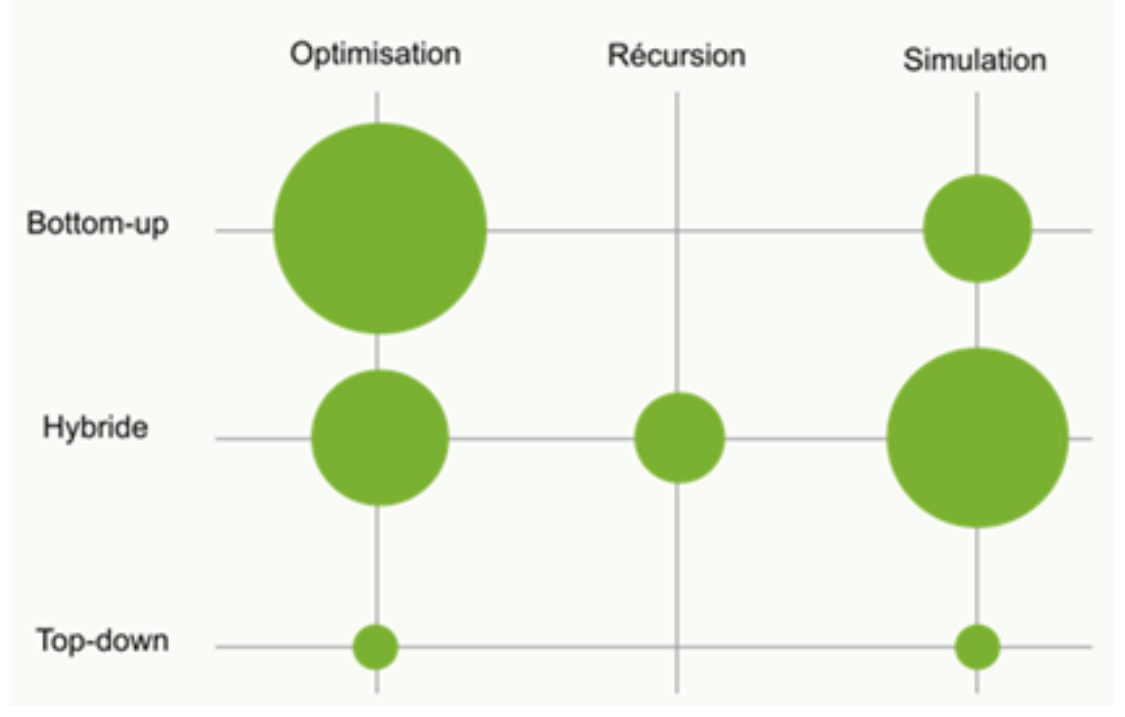

Source: ANCRE Survey

Simulation models are built to reproduce a real system in order to study its behavior. They do not calculate what should be done to achieve a given result, but illustrate what might happen in a predefined situation. In contrast, optimization models assume the definition of an objective function: it is a quantity to be minimized or maximized (sum of costs, collective well-being, etc.). Finally, the recursive approach is at the intersection of the two previous techniques. Because of their size, these models can be constructed by simplifying the decision-making process: economic agents optimize an objective function recursively.

The scientific literature proposes various classifications of models used by energy, economy, and environment researchers (Percebois and Hansen, 2010; Bhattacharrya and Timilsina, 2010; Vieille-Blanchard, 2011; Nicolas, 2016; etc.). They all differ but nevertheless agree on some key elements that would need to be included in any typology:

- the analytical approach chosen: engineer or economic model, bottom-up or top-down approach, partial or general equilibrium

- the numerical methodology: optimization or simulation 
Computer tool recensions (Connolly et al., 2010; Sinha and Chandel, 2014) conclude that none of the existing tools allow for a complete vision of all the integration challenges and that every modeler selects or builds one tool to answer some specific questions. Tools are thus scaled to answer integration questions on very diverse objects (a building, a local, national or theoric system) and some of the other parameters included in the models (sector description, time step, etc.) prevent the comparison of results.

The disparity of models and of the results they propose is often considered to be a problem, especially by policymakers for whom it is difficult to read these different results and who then struggle to transform it into effective policy. According to our survey results, modelers consider that the difference in the starting hypothesis is key to this disparity. Databases used on technology costs can differ but a more structural point is that models are built to answer different kinds of questions and the current research state of play does not allow for the building of a model that would integrate the entire ongoing questioning. The ways models are structured differ according to their goal:

- Some choose between the physical aspect (network modeling) and the monetary aspect.

- Some are efficient in observing the behavior of a network in one given year but struggle with the projection of a system evolution over a longer period of time.

- The time granularity of a model affects both its efficiency and its results: traditionally, networks are modeled hourly, infra-hour models remain mostly the prerogative of transmission system operators for short-term simulations because of the computing power needed for such projections. Whether it is appropriate or not to build infra-hour models outside of this type of exercise is debated among the scientific community: it 
often means that some "average weeks" are modeled and processed without assurance that critical moments are being taken into account and detected by the model.

- The spatial features of networks (size, configuration, meshed aspect or not, obsolescence, etc.) and of the areas considered (sunshine, population, land use) affect the dimensioning of models and their results. The two extreme cases of a power system in a developing country of the equatorial belt, with few connections, small extensions, and many islanded parts, and a very large European network in a temperate zone, highly meshed and interconnected, cannot be directly compared.

Two conclusions can be derived from these observations. First it is impossible, given the current research state of play, to obtain an immediate global convergence of results. Both models and questionings are not mature enough on these quite recent objects and the discrepancies one can find in the results show precisely the wide remaining uncertainties. Second, such a convergence is not currently desirable as the models and scenarios' precise purpose is to answer and reflect the diversity of the ongoing questionings through different approaches. It would be structurally impossible to ask that different questionings bring one single same answer, even though it would be easier for policymaking or communication.

However, a consensus among respondents points to some recurring difficulties in current modeling dynamics. The impact modeling of emergent technologies is still fragile and must be improved to strengthen the pertinence of projections. The possible development of substitute low carbon emitting technology (other than solar and wind) is seldom considered. Some of the basic scenario data would benefit from being harmonized and more systematically shared (economic databases, technologies features such as costs, technology readiness level). From a more general viewpoint, a lack of transparency and sharing of both the data and methodologies used is often highlighted. 


\section{Potential research leads}

The value chain for the integration of variable RES into power networks is long and particularly complex. Each element raises specific challenges (whether technical or not) and opens a specific research field. The interactions and interdependencies between these elements are also important, which makes a global vision on the topic difficult. What could be the potential research leads that would benefit some attention from the research community? We do not pretend to enter into very technical details, the point here is rather to account for the critical perspective in ongoing research dynamics that derived from both the bibliometric and survey analysis.

\subsection{Current important topics}

The panel of survey respondents defined and ranked the factors for a good integration of the variable RES (Figure 13). The following results show that there is once again no single and easy answer but rather a panel of solutions that need to be combined. Political and social aspects of the problem appear rather weak in this classification which could also be explained by the under-representation of social sciences among the respondents. 
Figure 13: Most important factors for the integration of variable RES into the power network

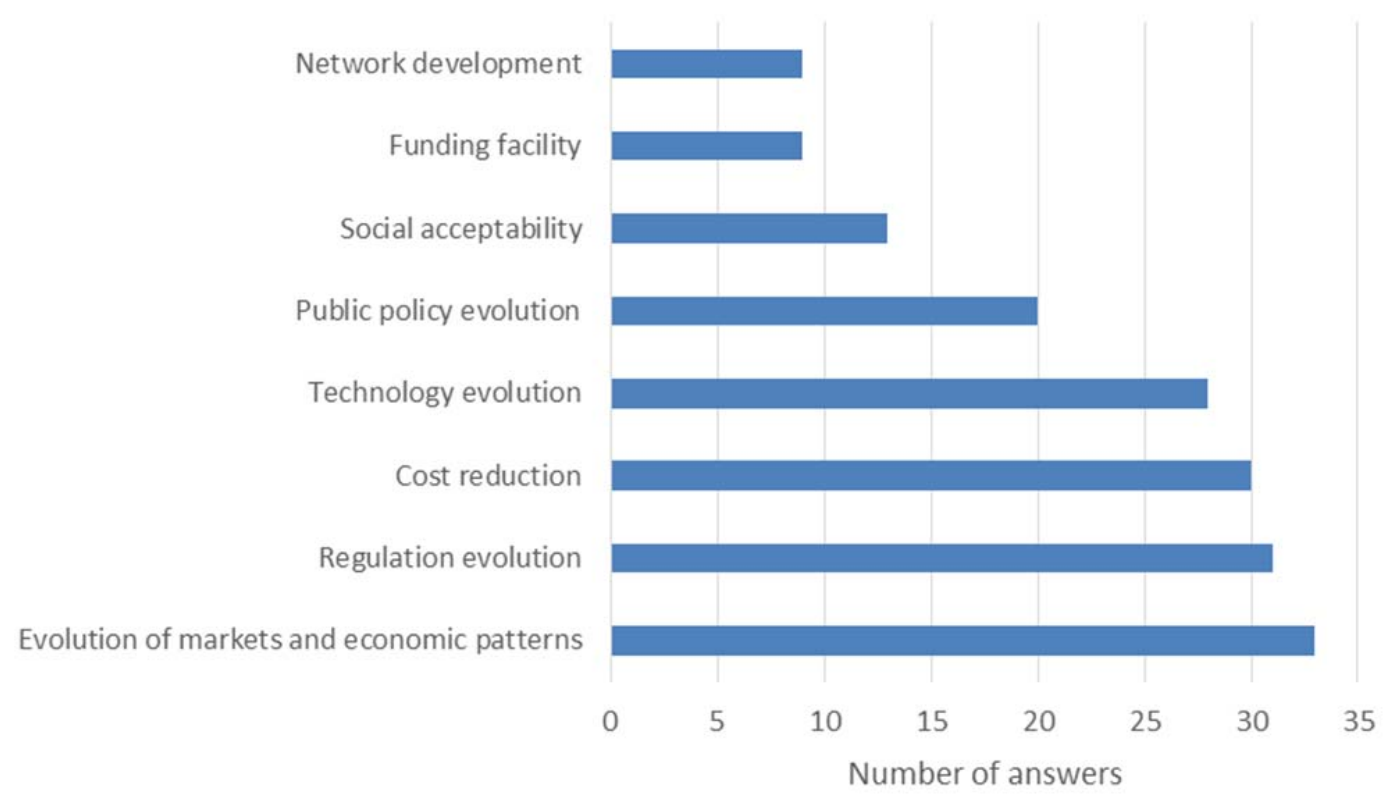

Source: Scopus/Intellixir

* This figure can be read as follow: 33 respondents consider the Evolution of Markets and economic patterns as the most important factors for the integration of variable RES into the power network.

The same identification and ranking has been done for important technologies and the same pattern emerges. If storage and flexibility appear at the top of the list, most of the comments may point at the impossibility of achieving this integration without simultaneously considering all the technological evolutions. The optimal balance between them will then vary depending on local conditions in every network (Figure 14). 
Figure 14: Most needed technology development

(number of answers*)

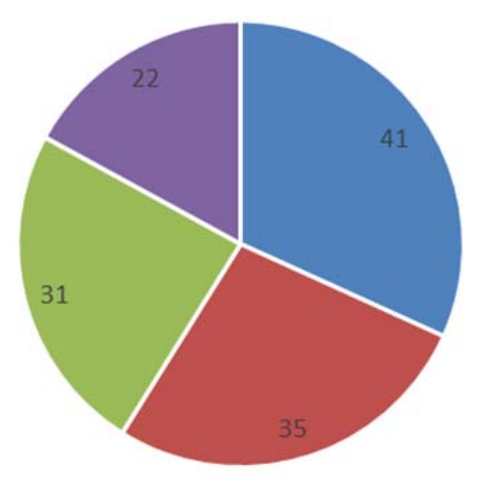

- Storage

- Flexibility

- Demand Side Management

- Integrated Management of Power systems

Source: ANCRE Survey

* This figure can be read as follow: 41 respondents storage as the most needed technology development.

\subsection{Unresolved challenges}

\section{a) Technical aspects}

Modeling exercises choose between either a focus on network stability, economic dimension, consumer behavior, or market design, etc. To our knowledge there is no existing model that takes into account all of these elements at the same time and that integrates them. The following results derive from the verbatim brought by the survey, they present the challenges that the scientific community considers as unresolved or in progress.

On the technical side, network stability (and frequency stability) is one of the key elements for variable RES integration which often acts as a disturbing factor. This stability challenge covers frequency control, planning, and the building of new lines and the management of the network's kinetic energy and reserves. Studying all these complex factors and how they interact in one model is difficult. For example, short-term storage, demand-side response, and storage dimensioning (intraday or seasonal) are aspects which are mentioned in certain studies 
but are seldom quantified or their dimensioning remains qualitative which does not allow for them to be integrated in currently developed models. The market structure regarding the tools for this stability is also rarely taken into account: should it be centralized or are we heading toward a decentralized market with, for example, stabilizing and monitoring tools installed directly in private individual residences or in industrial facilities?

Flexibility and seasonal aspects are a second type of challenge that needs research development. From a pure technical perspective, some of the existing optimization options are way less studied and taken into account than others (transforming a substation carrying the capacity for variable RES, margin of security of the old power station in the current evolving conditions of monitoring, etc.). The development of flexibility services would also benefit from a larger perspective. Often, only a few flexibility options are considered (certain types of battery storage, demand-side management, production flexibility, interconnection, etc.): the focus is thus only placed on the energy sector when other opportunities could be found in related sectors such as transportation and heating. The impact of these operational aspects on the long-term decision investment is often not considered: the challenge of flexibility is not an upstream concern but rather a downstream one that comes up when the investment decision is made. In the same perspective, most of the studies use a static demand/supply balance, thus underestimating the networks' or the production's operational margin and reserves used to operate the system in a dynamic way. The dynamic functioning of the system is often not addressed, along with the information and monitoring systems of production facilities and the market design challenges it brings up. Distribution networks are less studied than transport networks, even though they absorb a large part of the RES decentralized production whose frequency response is very quick. Storage is conversely widely studied but some challenges call for deeper studies without limitations to the mere question of flexibility. Storage during low-production episodes remains mostly unstudied because of its complexity and its cost (but 
market studies should envision every situation) and the role batteries could play, especially associated with vehicle fleets, calls for a better understanding.

\section{b) Markets and financing aspects}

The market design that would be most suitable for the integration of variable RES into power systems is still a gray area for research. This uncertainty creates an investment risk for the different players of the value chain. The market design is a major question for researchers as it includes a vast number of concepts: risk management, types of contracts, adaptability and adaptation of the network, time horizon, etc. The regulatory aspects and their evolution are particularly important in this context, both at the national level but also in their local aspects specific to each area. Their evolution and impact are still poorly studied in the literature.

The cost impacts at all levels of the value chain are still debated. At the production level, the level of financing and investment required for the development of variable RES is unclear and depends on the political vision of the evolution of the electricity supply in the short, medium and long term. At the level of the transmission and distribution network, the question of pricing arises: is it necessary to charge the consumer the access service to the network in addition to the demand for power to compensate for the losses associated with a new category of consumer-producers who only use the network as a backup of their own production? And if so, in what proportions? At the level of consumption, how should the evolution of the price of electricity be modeled? The variable RES production means, which are currently the first in the "merit order" of production sources, are pushing out of the conventional power plants market which are unprofitable in the current market design and are dismantled or mothballed without guarantee so that the original production intermittent renewable energy can ultimately ensure the satisfaction of the entire demand. Conversely, some wind or solar projects with almost zero margins can be threatened if the price of electricity drops, held in place only to guarantee a price system, as is the case in current tenders. 
Generally speaking, the economic dimension of the problem of integrating variable RESs into electrical networks is still poorly taken into account and the models are insufficiently detailed, particularly with regard to:

- the additional cost of storage in the final cost of energy;

- the cost of the environmental, health, and social impact of the new high-voltage lines;

- the cost of the intermittency of the variable RES;

- the economic value of the MWh of the additional variable RES capacities. One often imposes a level of development (share in electrical energy at a precise date) without worrying about the gradual decline in the value of the MW of renewable energy as installations progress; the possible technological breaks announced;

- the good representation of the various stages of the electricity markets to develop the flexibility services trade (reserve market, adjustment market, intraday market), as well as all the electrical equipment with its flexibility character (equipment ramping, conventional, production hazards on PV and wind types) in a model market with unit commitment;

- the demand and its possible flexibility, which is generally much less studied in detail than the "supply side" (means of production and storage, and transport infrastructure, etc.).

\section{c) Social aspects}

The behavior of citizens and consumers in the development of large sources of variable RES production are not taken into account in the modeling exercises or in the scenario. Considered as a field of research specific to the social sciences, this topic is still not taken into account enough by the scenario designers. Yet the issues of social acceptability by citizens (for the establishment of new production or transport infrastructure) and the change in consumer 
behavior (the ecological choices made by individuals or the responsiveness to a given price signal on the electricity) partly condition the results. Despite the general support of the population for this type of policy, the cost to consumers or the taxpayers of the transition to an electricity system with a high rate of integration of variable RES, may in some cases lead to populations being "fiscally fed up" which may lead to a mistrust regarding the need to reduce the global carbon footprint. On the other hand, it is interesting to examine the influence of crowdfunding on the deployment and localization of renewable energy (Lam and Law, 2016; Vasileiadou et al., 2016). Financing is an important barrier for variable RES and the new systems put in place (including crowdfunding platforms) are currently being developed to encourage the placement of local savings, whether in developed or in developing countries. The financial aspects of the development of variable RES are rarely taken into account in energy transition models. As a key element for the integration of variable RES in the power networks, they should be studied more because they cover geographic issues (criterion of residence for the investors and savings reserves, to favor the local anchoring of the projects) and issues related to the participation of the citizens. Eventually all the questions related to the social acceptance of the projects and the way to address the well-known "Not In My BackYard" (NIMBY) or "Build Absolutely Nothing Anywhere Near Anything“ (BANANA) problems need further addressing. The issue of governance for the management of these new sources of intermittent production needs to be further explored. The installation of variable renewable energy infrastructures has local impacts (land, landscape, etc.) and is associated with a particular experience of the populations concerned. It may be a feeling of "take-back," local control of the sources of energy production and supply, or a feeling of imposition by a centralized and distant power of infrastructure that does not serve the interests of the local population (impact on crops or tourism, for example). These questions relating to the local specificities of projects require the upstream consideration of investment decisions if we wish 
to establish a constructive dialogue between stakeholders around the common objective of promoting and facilitating the development of variable RES. These are important topics for the deployment of variable RES that should be integrated into the modeling exercises in order to cope with the objectives of public policy recommendations for the political body (Ribeiro et al., 2018).

\section{d) The need for a systemic vision}

The scenarios (or the model) often study one aspect of the question of the integration of variable RES (adequacy of the production means, reliability of the electricity grid, power markets design, etc.) without presenting a systemic vision of the question (which would take into account technical, legal, behavioral issues, etc.). The complexity of the questions and the organization of the research (in silos) is explained by the multiple nature of the questions asked. It is currently difficult to work on the global picture of the problem which would require us to integrate all of its components, insofar as interactions and feedback effects exist between them. More broadly, the integration of variable RES into electricity grids is influenced by elements that lie outside the power system. It is necessary to take into account energy needs other than electricity (heat, cooling, water, energy for transport...) in order to consider all aspects of the problem. Similarly, it is necessary to take into consideration the other energy vectors aside from electricity, and the possible interconnections between networks and possible inter-conversions between energy vectors (especially storage).

\section{Conclusion and Policy Implications}

Integration of variable RES into power networks has been a trending research topic for the last decade. The complexity of the envisioned problems often leads to very specific papers focusing on one aspect of the problem in a silo approach. The comparison between trends revealed by the bibliographic analysis and needs expressed by the respondents to our survey 
among researchers in the field thus shows some discrepancies. More than half of the respondents mention the political body and the network operators as the most important actors for a fast integration of the variable RES to the electricity networks whereas the research and the technological breakthrough it might bring appear only in $5^{\text {th }}$ position. The geographic scope of the current scenarios (let at a national level) is somehow contradictory to the need expressed for local studies. Among the interviewees, many modelers answered our questions and show a real diversity of models and methodologies used to treat the subject. The diversity and disparity of the research models and the results they propose is often presented as a problem. However, this disparity can be explained by many factors: lack of common databases on the costs of technologies and their evolution, for example, but also more structurally: diversity of the questions asked through these models. Therefore, in the current state of research, it is not possible to build a model that integrates all the current questions. The majority of the comments made by the researchers interviewed thus state not only an impossibility to converge the results of the various models but they also underline that this convergence is not desirable in the current state of research. The modeling exercises should be intended not to give the same results but to answer the diversity of the questions that research raises or to bring different and complementary insights, according to the qualities and limits specific to this or that model, on the same question. The disparity in the results of the models currently used is therefore the result of both a lack of maturity of research on these issues, which are relatively recent in their study (and which require complex tools as well as considerable computing power) and also of a structural impossibility to see different questions bring similar answers. However, some of the baseline data, such as economic databases and technology characteristics (costs, technology readiness level (TRL), etc.), would benefit from being harmonized and more widely shared. In general, a lack of transparency and the sharing of methodologies and data are sometimes emphasized. 
The integration of high variable renewable energy rates into electricity networks impacts the entire value chain of the power system and affects generation, transmission, distribution, and consumption. This also calls for an integrated approach. For each part of the value chain, there are specific technical issues, but research should also focus on transversal question such as governance, social, legal or political issues. Generally speaking, the question of the cost and the economic profitability of the integration of variable RES arise at every part in the chain, but it is difficult to define an economic optimum taking into account the combination of the different evolutions of this value chain.

Current research on the integration of variable RES into power networks would benefit from leading the following actions: building a common database for modeling, including the cost of technologies and technology specifications, opening international collaborations, conducting researches with a global approach including social sciences and other sources of energy consumption (transport, heating, etc.). Researchers should also keep in mind that the topic stays very political: current market designs include wide subsidies and in many cases public opinion prevails over economic rationale.

\section{References}

Aleixandre-Benavent, R., Aleixandre-Tudó, J. L., Castelló-Cogollos, L., Aleixandre, J.L., 2017. Trends in global research in deforestation. A bibliometric analysis. Land Use Policy Volume 72, 293-302. https://doi.org/10.1016/j.landusepol.2017.12.060

Bhattacharyya, S.C., Timilsina, G.R., 2010. Modelling energy demand of developing countries: Are the specific features adequately captured? Energy Policy 38, 1979-1990. https://doi.org/10.1016/j.enpol.2009.11.079 
Chen, H-Q., Wang, X., He, L., Chen, P., Wan, Y., Yang, L., Jiang, S., 2016. Chinese energy and fuels research priorities and trend: A bibliometric analysis. Renewable and Sustainable Energy Reviews 58, 966-975. https://doi.org/10.1016/j.rser.2015.12.239

Chen, W., Liu, W., Geng, Y., Brown, M.T., Gao, C., Wu, R., 2017. Recent progress on energy research: A bibliometric analysis. Renewable and Sustainable Energy Reviews 73, 1051-1060. https://doi.org/10.1016/j.rser.2017.02.041

Connolly, D., Lund, H., Mathiesen, B.V., Leahy, M., 2010. A review of computer tools for analysing the integration of renewable energy into various energy systems. Applied Energy 87, 1059-1082. https://doi.org/10.1016/j.apenergy.2009.09.026

Criqui, P., Mima, S., 2012. European climate-energy security nexus: A model based $\begin{array}{llll}\text { scenario } & \text { analysis. } & \text { Energy } & \text { Policy }\end{array}$ https://doi.org/10.1016/j.enpol.2011.11.061

[dataset] Hache, E., Palle, A., 2017, Analytic table of the recent bibliography on bibliometric studies in energy and environmental fields (Scopus)

[dataset] Hache, E., Palle, A., 2017, Integration of variable RES into power networks, scenario papers analysis (Scopus)

[dataset] Hache, E., Palle, A., 2017, Integration of variable RES into power networks, ANCRE survey

Fabianne de Paulo, A., Silveira Porto, G., 2017. Solar energy technologies and open innovation: A study based on bibliometric and social network analysis. Energy Policy 108, 228-238. https://doi.org/10.1016/j.enpol.2017.06.007

Gao, C., Sun, M., Geng, Y., Wu, R., Chen, W., 2016. A bibliometric analysis based review on wind power price. Applied Energy 182, 602-612. https://doi.org/10.1016/j.apenergy.2016.08.144 
Geng, S., Wang, Y., Zuo, J., Zhou, Z., Du, H., Mao, G., 2017. Building life cycle assessment research: A review by bibliometric analysis. Renewable and Sustainable Energy Reviews 76, 176-184. https://doi.org/10.1016/j.rser.2017.03.068

Geng, Y., Chen, W., Liu, Z., Chiu, A.S.F., Han, W., Liu, Z., Zhong, S., Qian, Y., You, W., Cui, X., 2017. A bibliometric review: Energy consumption and greenhouse gas emissions in the residential sector. Journal of Cleaner Production 159, 301-316. https://doi.org/10.1016/j.jclepro.2017.05.091

Han, M.Y., Sui, X., Huang Z.L., Wu X.D., Xia X.H., Hayat T., Alsaedi A., 2014. Bibliometric indicators for sustainable hydropower development. Ecological Indicators 47, 231-238. https://doi.org/10.1016/j.ecolind.2014.01.035

Lam, P.T.I., Law, A.O.K., 2016. Crowdfunding for renewable and sustainable energy projects: An exploratory case study approach. Renewable and Sustainable Energy Reviews 60, 11-20. https://doi.org/10.1016/j.rser.2016.01.046

Li, W., Zhao, Y., 2015. Bibliometric analysis of global environmental assessment research in a 20-year period Environmental Impact Assessment Review 50, 158-166. https://doi.org/10.1016/j.eiar.2014.09.012

Loulou, R., Labriet, M., ETSAP-TIAM: the TIMES integrated assessment model Part I: Model structure, Computational Management Science, February 2008, Volume 5, Issue $1-2$, pp. $7-40$.

Loulou, R., Goldstein, G., 2005. Documentation for the TIMES Model PART II.

Mao, G., Huang, N., Chen, L., Wang, H., 2018. Research on biomass energy and environment from the past to the future: A bibliometric analysis. Science of the Total Environment 635, 1081-1090. 10.1016/j.scitotenv.2018.04.173 
Merigó, J.M., Yang, J-B.,2017. A bibliometric analysis of operations research and management science. Omega 73, 37-48. https://doi.org/10.1016/j.omega.2016.12.004

Nicolas, C., 2016. Robust energy and climate modeling for policy assessment. Université Paris Ouest Nanterre-La Défense, Paris.

Percebois, J., Hansen, J.-P., 2010. Energie : Economie et politiques, Ouvertures économiques. De Boeck.

Ribeiro, F., Ferreira, P., Araújo, M., Braga, A-C. (2018) Modelling perception and attitudes towards renewable energy technologies, Renewable Energy, Available online 3 February 2018, ISSN 0960-1481, https://doi.org/10.1016/j.renene.2018.01.104.

Sinha, S., Chandel, S.S., 2014. Review of software tools for hybrid renewable energy systems. Renewable and Sustainable Energy Reviews 32, 192-205. https://doi.org/10.1016/j.rser.2014.01.035

Tiana, X., Geng, Y., Zhong, S., Wilson, J., Gao, C., Chen, W., Yu, Z., Hao, H., 2018. A bibliometric analysis on trends and characters of carbon emissions from transport sector. Transportation Research Part D: Transport and Environment, Volume 59, 1-10. https://doi.org/10.1016/j.trd.2017.12.009

United Nations Environment Programme, Bloomberg New Energy Finance, (2018).

Global trends in renewable energy investment 2018, 86p. http://fs-unepcentre.org/sites/default/files/publications/gtr2018v2.pdf

Vasileiadou, E., Huijben, J.C.C.M., Raven, R.P.J.M., 2016. Three is a crowd? Exploring the potential of crowdfunding for renewable energy in the Netherlands. Journal of Cleaner Production 128, 142-155. https://doi.org/10.1016/j.jclepro.2015.06.028 
Vieille Blanchard, E., 2011. Les limites à la croissance dans un monde global - Modélisations, prospectives, réfutations. EHESS, Paris.

Wang, L., Zhao, L., Mao, G., Zuo, J., Du, H., 2017a. Way to accomplish low carbon development transformation: A bibliometric analysis during 1995-2014. Renewable and $\begin{array}{llllll}\text { Sustainable } & \text { Energy } & \text { Reviews } & \text { 68, }\end{array}$ https://doi.org/10.1016/j.rser.2016.08.021

Wang, L., Wei, Y-M., Brown, M.A, 2017b. Global transition to low-carbon electricity: A bibliometric analysis. Applied Energy Volume 205, 57-68. https://doi.org/10.1016/j.apenergy.2017.07.107

Wei, Y-M., Mi, Z-F., Huang, Z., 2015. Climate policy modeling: An online SCI-E and SSCI $\begin{array}{lllll}\text { based } & \text { literature } & \text { review. } & \text { Omega }\end{array}$ https://doi.org/10.1016/j.apenergy.2016.07.129

Yu, H., Wei, Y-M., Tang, B-J., Mi, Z., Pan, S-Y., 2016. Assessment on the research trend of low-carbon energy technology investment: A bibliometric analysis. Applied Energy 184, 960-970. https://doi.org/10.1016/j.apenergy.2016.07.129

Zhang, K., Wang, Q., Liang, Q-M., Chen, H., 2016. A bibliometric analysis of research on carbon tax from 1989 to 2014. Renewable and Sustainable Energy Reviews 58, $297-$ 310.

Zhang, Y., Huang, K., Yu, Y., Yang B., 2017 Mapping of water footprint research: A bibliometric analysis during 2006-2015. Journal of Cleaner Production 149, 70-79. https://doi.org/10.1016/j.jclepro.2017.02.067 